\title{
PKM KERAJINAN KERANG DI BANJAR LODALANG DESA KUKUH MARGA TABANAN
}

\section{PKM of Hand Craft Shells in Banjar Lodalang Desa Kukuh Marga Tabanan}

\author{
Ni Putu Linda Santiari ${ }^{1 *}$, Ni Luh Putri Srinadi², I Gusti Rai Agung Sugiartha ${ }^{3}$ \\ ${ }^{1,2,3}$ STMIK STIKOM Bali \\ Jalan Raya Puputan No.86 Renon, Denpasar, Bali \\ Telepon (0361) 244445 \\ e-mail korespondensi: linda_santiari@stikom-bali.ac.id ${ }^{1^{*}}$, putri@stikom-bali.ac.id ${ }^{2}$, \\ sugiarta@stikom-bali.ac.id ${ }^{3}$
}

\begin{abstract}
ABSTRAK
Desa Kukuh merupakan salah satu dari 16 Desa yang ada di Kecamatan Marga. Komuditi utama dari desa ini adalah kerajinan berbahan kayu, batu padas, dan kerang. Dalam program kemitraan masyarakat (PKM) ini melibatkan 2 UKM yang mempunyai bidang kerajinan yang sama, yakni dengan bahan baku kerang. Kedua Mitra menghasilkan produk yang hampir sama yakni seperti bokor, dulang, dan sokasi. UKM pertama adalah Kerang Bali yang berdiri pada tahun 2012 sedangkan UKM kedua adalah Mozaik Hindu Bali berdiri pada tahun 2006. Kedua UKM Mitra ini menghasilkan produk yang hampir sama yakni seperti bokor, dulang, dan sokasi. Terdapat beberapa kendala utama yang dihadapi oleh kedua UKM antara lain terbatas atau manualnya peralatan yang digunakan untuk menghasilkan produk, kurangnya pengetahuan UKM dalam memhasilkan variasi produk, kurangnya cara pengemasan produk, tidak adanya label sebagai identitas UKM, kurangnya pengetahuan pengelolaan manajemen keuangan serta terbatasnya cara pemasaran produk. Berdasarkan kendala dan permasalahan utama yang dihadapi oleh kedua Mitra maka kegiatan yang telah dilaksanakan adalah pemberian alat produksi yang dapat membantu meningkatkan jumlah produksi seperti alat bor duduk, mesin gerinda, mesin kompresor, dan spray gun untuk melakukan finishing. Hal ini akan membantu menghasilkan jumlah produk yang stabil atau meningkat. Pembuatan dan pelatihan pemasaran secara online berupa akun sosial media. Berdasarkan hasil evaluasi kegiatan telah dicapai luaran kegiatan yaitu jumlah produksi mengalami peningkatan sebanyak 50\%, peningkatan pendapatan mitra hingga 50\%, seluruh anggota UKM dapat membuka dan mengelola akun sosial media.
\end{abstract}

Kata Kunci: PKM, Kerajinan, Kerang

\section{ABSTRACT}

Kukuh Village is one of 16 villages in Marga Subdistrict. The main commodities of this village are handicrafts made from wood, stone, and shells. In the community partnership program (PKM) this involves 2 UKM who have the same craft field, namely with raw material shells. Both Partners produce almost the same products, such as Bokor, dulang, and sokasi. The first UKM was Bali Shellfish which was established in 2012 while the second UKM was Bali Hindu Mosaic established in 2006. Both of these UKM Partners produced almost the same products, such as bokor, dulang, and sokasi. There are several main constraints faced by the two UKM, including limited or manual equipment used to produce products, lack of knowledge of UKM in producing product variations, lack of product packaging methods, the absence of labels as UKM identities, lack of financial management knowledge and limited marketing methods. product. Based on the main constraints and problems faced by the two Partners, the activities that have been carried out are the provision of production equipment that can help increase the number of products such as a sitting drill, grinding machine, compressor machine, and spray gun for finishing. This will help produce a stable or increasing number of products. Making and marketing training online in the form of social media accounts. Based on the results of the activity evaluation, the output of the activity has been achieved namely, the amount of production has increased by $50 \%$, the increase in partner's income by 50\%, all members of UKM can open and manage social media accounts.

Keywords: PKM, Craft, Shell

Available at http://jurnal.borneo.ac.id/index.php/jpmb 


\section{PENDAHULUAN}

Salah satu kerajinan unggulan Kabupaten Tabanan adalah kerajinan dari kerang. Desa Kukuh, Kecamatan Marga merupakan salah satu desa pengrajin kerang. Desa Kukuh adalah salah satu desa dari 16 desa di Kecamatan Marga dengan jarak $8 \mathrm{Km}$ di sebelah utara Kota Tabanan. Jarak Desa Kukuh dengan STIKOM bali sekitar $28 \mathrm{Km}$. Komuditi utama dari desa ini adalah kerajinan berbahan kayu, batu padas, dan kerang (Arimbawa, dkk 2010). Diantara hasil kerajinan ini, kerajinan kerang merupakan komiditi yang sangat prospektif. Dalam program kemitraan masyarakat (PKM) ini melibatkan 2 UKM yang mempunyai bidang kerajinan yang sama, yakni dengan bahan baku kerang. 2 UKM Mitra ini menghasilkan produk yang hampir sama yakni seperti bokor, dulang, dan sokasi seperti yang terlihat pada Gambar 1. dan Gambar 2. karena sebagian besar masyarakat Bali menganut agama Hindu. Dari hal inilah poara kedua UKM Mitra ini lebih banyak menghasilkan produk yang berfokus pada kebutuhan persembahyangan yang digunakan oleh masyarakat Bali. Selain itu dari segi pengetahuan diversifikasi produk 2 UKM Mitra ini masih kurang.

UKM pertama adalah Kerang Bali yang berdiri pada tahun 2012, saat ini telah memiliki karyawan sebanyak 4 orang dimana masing-masing karyawan mempunyai tugas dan fungsinya masingmasing. Produk yang dihasilkan selama ini hanya mencakup cermin, bokor, dulang, dan sokasi. Untuk cara pemasarannya pun masing terbilang tradisonal, yakni dengan menitipkan barang produksi pada pasarpasar setempat ataupun toko-toko yang memungkinkan menjual barang-barang untuk keperluan persembahyangan. Karena pemilik UKM Mitra ini minim pengetahuan di bidang teknologi informasi. UKM kedua adalah Mozaik Hindu Bali berdiri pada tahun 2006, saat ini UKM ini telah memiliki 3 karyawan. Untuk produk yang dihasilkan hampir sama dengan UKM Kerang Bali yaitu produk yang berfokus pada kebutuhan persembahyangan Umat Hindu berupa bokor, dulang, dan sokasi. Tidak jauh berbeda dengan UKM Kerang Bali cara pemasaran dari UKM Mozaik Hindu Bali ini juga terbilang masih sangat sederhana, dengan cara memasarkan door to door. Bahkan terkadang mereka harus menerima perlakuan yang tidak menyenangkan dari para konsumen seperti penolakan yang kasar.

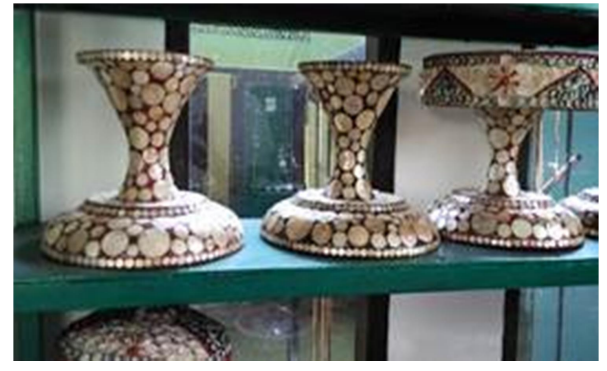

Gambar 1. Produk UKM Kerang Bali

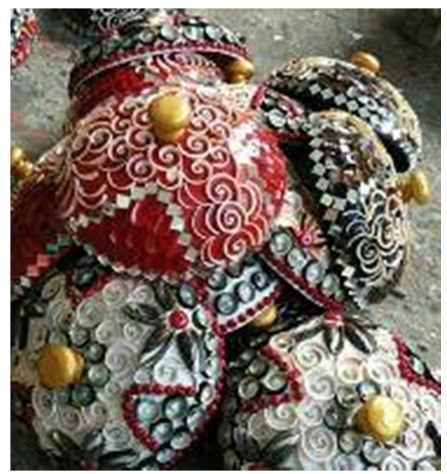

Gambar 2. Contoh Produk UKM Mozaik Hindu Bali

Kedua UKM ini memiliki permasalahan yang sama, baik dalam bidang produksi, manajemen, maupun pemasaran. Masalah dalam bidang produksi adalah kurangnya alat pendukung produksi seprti gerindra, mesib bor, alat untuk pengecatan dan mesin pengamplasan relatif sudah lama dan kualitasnya pun tidak baik. Menurut Bapak Made Wintara, bila alatnya bagus maka 
setiap harinya bisa menghasilkan paling tidak 100 unit kerajinan. Dalam bidang manajemen produk, kedua pengerajin tidak melakukannya dengan baik, sehingga produk-produk yang dihasilkan tidak memiliki spesifikasi. Hal ini disebabkan karena kurangnya pengetahuan pengrajin dari segi kemungkinan pengembangan jenis produk. Saat ini mitra tidak mengetahui dengan pasti pendapatan yang diperoleh karena tidak pernah melakukan pencatatan atau manajemen keuangan dan inventory. UKM juga memiliki pengetahuan yang minim dalam pengemasan produk, UKM hanya membungkus produk dengan plastik bening, tanpa adanya label profil UKM seperti yang terlihat pada Gambar 3 . Sedangkan apabila dilihat dari segi pengemasan yang menarik dapat meningkatkan nilai jual dan nilai tambah dari produk kerajinan tersebut.

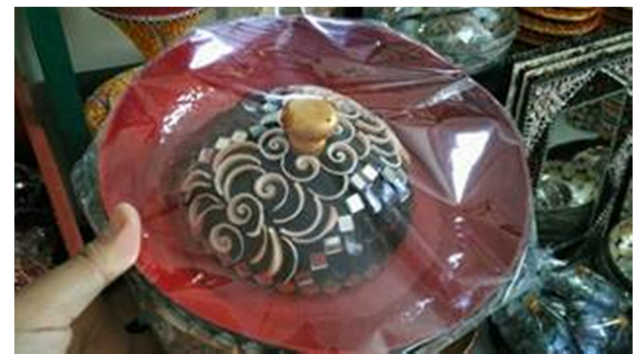

Gambar 3. Kemasan Produk UKM

Dampak eksistensi pengerajin ini terhadap lingkungannya diharapkan mampu meningkatkan kesejahteraan masyarakat disekitarnya karena ikut terlibat sebagai tenaga kerja. Bahkan, harapan selanjutnya adalah dapat dilahirkannya pengusahapengusaha baru dengan desain yang lebih kreatif. Dampak langsungnya adalah meningkatnya devisa bagi negara.

\section{METODE}

Pada metode pelaksanaan akan menggambarkan prosedur kerja yang akan dilakukan pada kegiatan ini. Prosedur kerja yang akan dilakukan pertama kali adalah memberikan sosialisasi terhadap mitra untuk mengetahui prosedur, informasi dan manfaat dari kegiatan ini. Setelah dilakukan sosialisasi yang selanjutnya dilakukan wawancara untuk mengetahui proses produksi dan pengelolaan keuangan mitra, melakukan pengamatan langsung mengenai proses produksi mitra. Selanjutnya akan dilakukan penentuan permasalahan dan proses selanjutnya adalah peningkatan kualitas dan jumlah produksi, pengemasan yang menarik untuk meningkatkan teknologi pemasaran serta manajemen keuangan. Proses kerja dalam kegiatan ini seperti yang digambarkan pada Gambar 4 . dibawah ini :

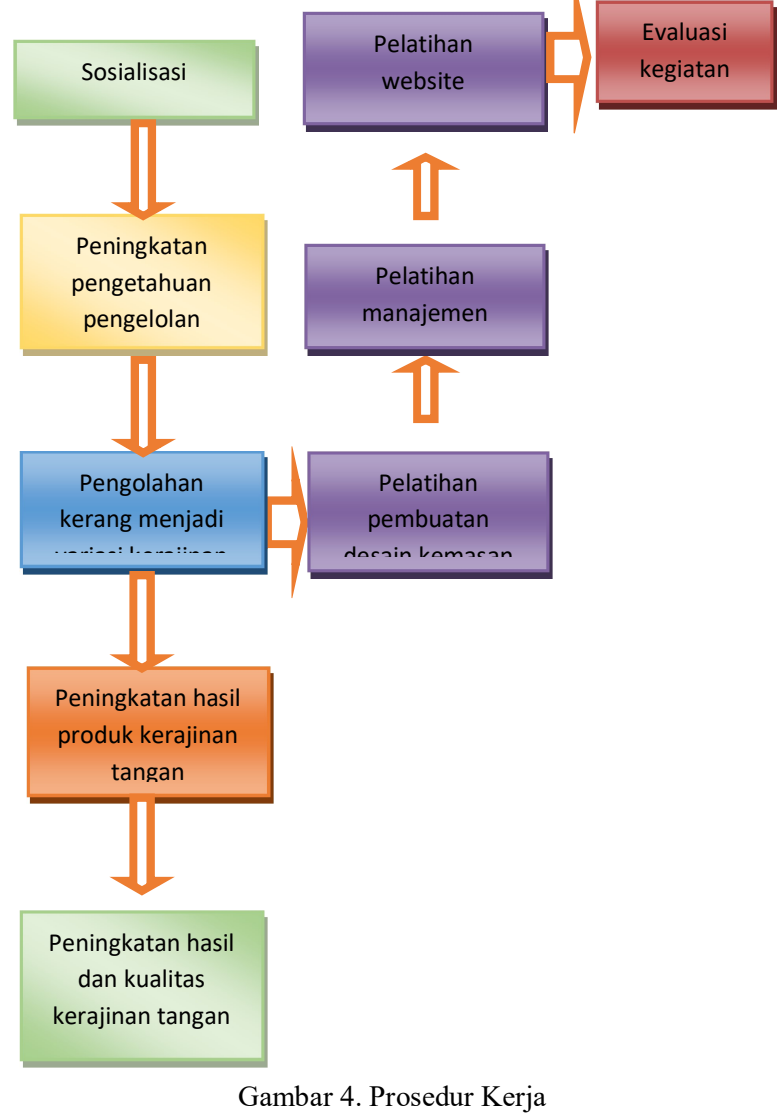

3. HASIL DAN PEMBAHASAN

\subsection{Sosialisasi Kegiatan}

Kegiatan sosialisasi serta pengarahan kegiatan dilakukan pada bulan Mei dimana peserta sosialisasi adalah kedua mitra yaitu 
pemilik UKM serta karyawan UKM Kerajinan Kerang. Materi sosialisasi diberikan oleh Linda Ni Putu Linda Santiari, S.Kom.,M.Kom, I Gusti Agung Rai Sugiartha, ST,MT, Ni Luh Putri Srinadi, SE.,MM.Kom. Pada saat sosialisasi telah disampaikan bahwa kegiatan lolos pendanaan serta disampaikan informasi - informasi mengenai latar belakang kegiatan, target kegiatan, sasaran kegiatan, dan tujuan kegiatan. Dimana seluruh kegiatan tersebut memiliki tujuan yaitu berkelanjutan dalam pengembangan fasilitas sarana dan prasarana mantra serta peningkatan hasil penjualan mitra. Pada saat kegiatan sosialisasi disampaikan juga rencana jadwal kegiatan pengabdian yang akan berlangsung.

\subsection{Penyerahan Alat Produksi}

Dari hasil analisa dan diskusi dengan mitra pada saat sosialisasi, terdapat beberapa peralatan yang dibutuhkan untuk meningkatkan jumlah produksi kedua mitra. Penyerahan barang dilakukan pada tanggal 16 Juni 2018 ke masing - masing mitra dan diterima oleh pemilik UKM langsung. Terdapat beberapa alat - alat bantuan yang diberikan kepada mitra adalah sebagai berikut :

1. Mesin Kompresor.

Mesin Kompresor diberikan kepada kedua mitra. Alat ini digunakan pada saat pengecatan barang agar lebih merata dan mengefektifkan penggunaan cat.

2. Bor Duduk.

Bor duduk diberikan kepada kedua mitra. Alat ini digunakan untuk mendukung pemasangan alat pada barang produksi.

3. Gerinda.
Gerinda diberikan kepada kedua mitra, dimana alat ini digunakan dalam proses pemotongan kerang dan kaca.

4. Spray Gun

diberikan kepada kedua mitra. Alat ini digunakan pada saat pengecatan barang agar lebih merata dan mengefektifkan penggunaan cat.

Berikut ini dokumentasi pada saat penyerahan bantuan alat produksi pada Mitra yaitu pada Gambar 5.

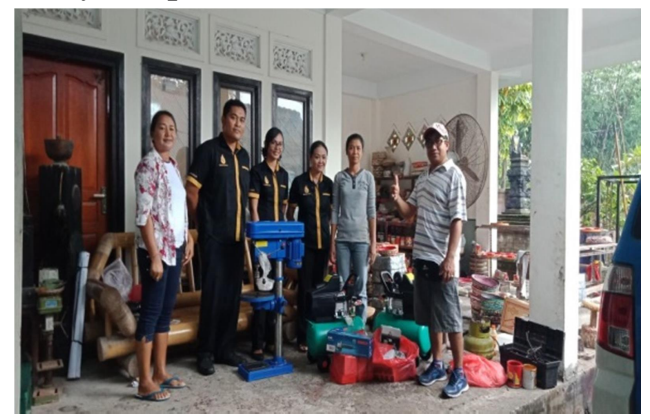

Gambar 5. Penyerahan Alat

\subsection{Pelatihan Penggunaan Alat}

Pelatihan penggunaan alat dilakukan setelah seluruh alat diserahkan ke kedua mitra. Mitra diajarkan untuk penggunaan alat agar dapat digunakan dalam proses produksi. Pelatihan penggunaan alat diberikan oleh tenaga yang memang paham penggunaan alat tersebut. Adapun dokumentasi penggunaan alat dapat dilihat pada Gambar 6.

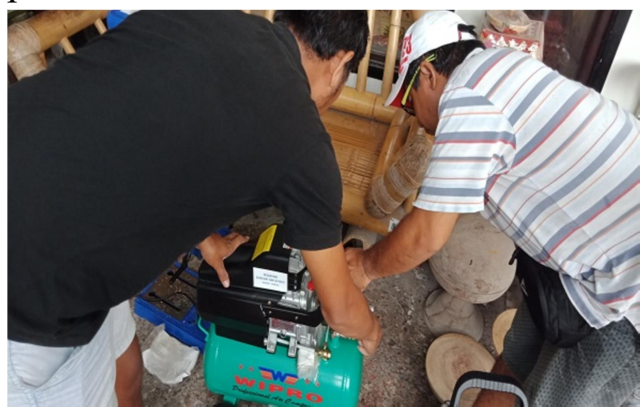

Gambar 6. Pelatihan Alat

\subsection{Pembuatan dan Pelatihan Media Pemasaran Online}

Pemasaran merupakan salah satu permasalahan yang ditangani dalam 
kegiatan ini, hal ini dikarenakan kedua mitra memiliki kendala dalam memasarkan dan memperkenalkan barang hasil produksi dalam hal ini kerajinan kerang. Pemasaran yang dilakukan selama ini adalah datang langsung ke pasar - pasar dan warung warung untuk menawarkan barang. Cara tersebut dirasakan kurang maksimal sehingga dibuatkan media pemasaran online untuk membantu pemasaran barang. Masing - masing mitra dibuatkan akun sosial media yaitu facebook dan instagram sehingga profil dan foto - foto barang yang dimiliki mitra dikumpulkan dan diunggah pada akun masing - masing mitra. Dengan adanya akun facebook dan instagram ini diharapkan mempermudah mitra dalam memasarkan produk serta mempermudah calon konsumen melakukan pemesanan barang. Akun facebook mitra Mozaik Hindu Bali dapat diakses melalui fanspage @mozaikkerangbali serta mitra Bali Kerang dapat diakses melalui @balikerang. Halaman facebook kedua mitra dapat dilihat pada Gambar 3.

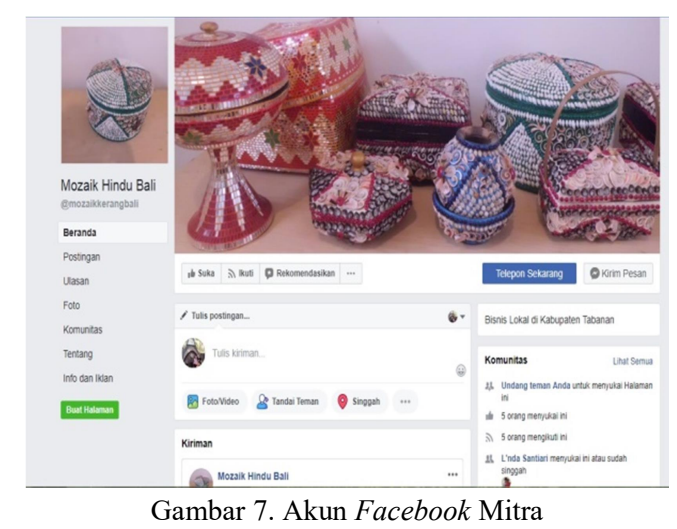

Untuk pemasaran online kedua mitra juga dibuatkan akun instagram dimana Mozaik Hindu bali memiliki akun dengan nama mozaikhindu_bali sedangkan bali kerang dengan nama balikerang.bali. Halaman utama dari masing - masing akun dapat dilihat pada Gambar 8.

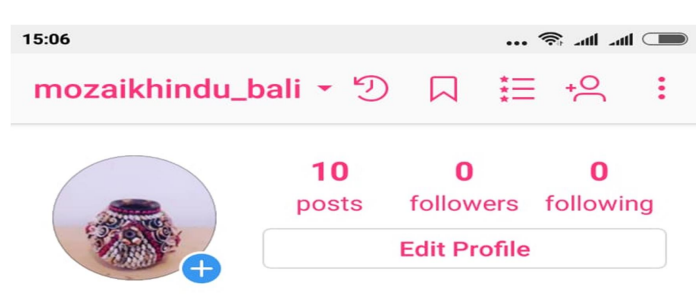

Mozaik Hindu Bali

Mozaik Hindu Bali (Pengrajin Kerang)

Jalan Alas Kedaton, Banjar Lodalang, Desa Kutuh, Marga,Tabanan

Pemesanan : 082247042725

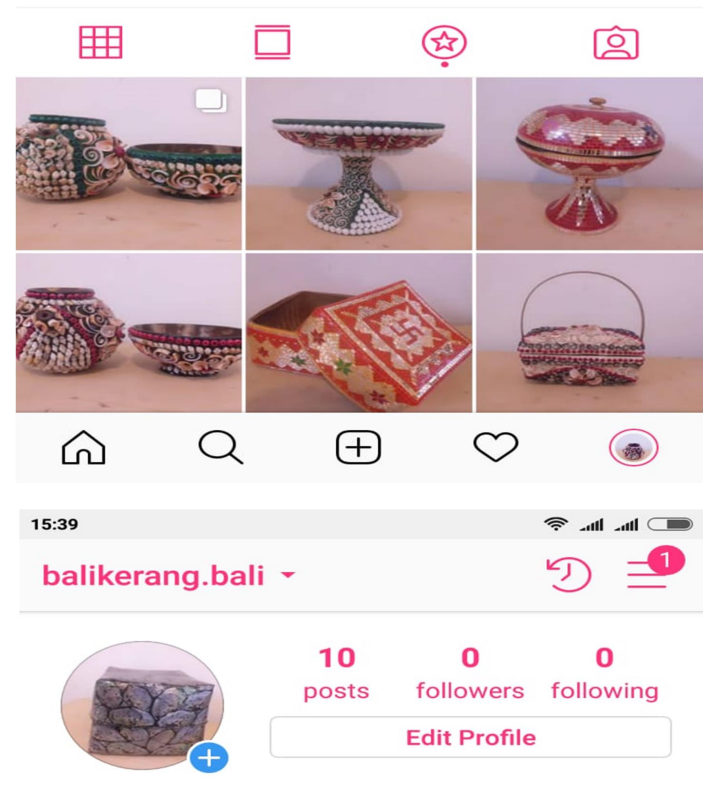

Bali Kerang

Bali Kerang(Pengrajin Kerang, Sarana Upakara)

Jalan Alas Kedaton, Banjar Lodalang, Desa Kukuh,

Marga, Tabanan, Bali

Pemesanan : 08123660232

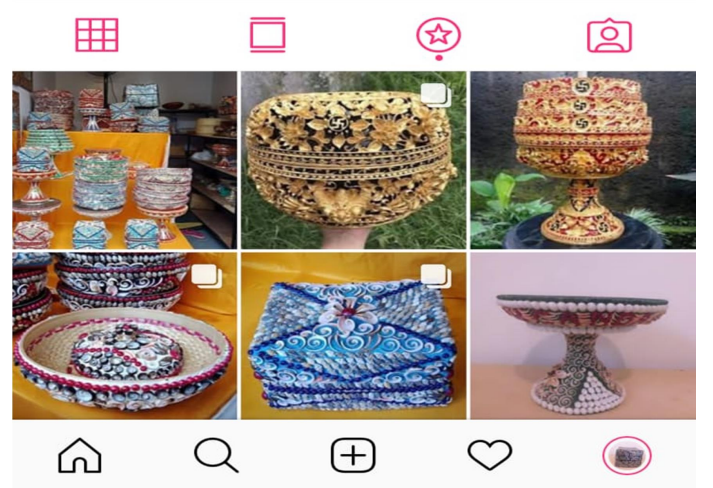

Gambar 8. Halaman Instagram Mitra

Kedua UKM mitra diberikan pelatihan pemanfaatan sosial media untuk pemasaran online, agar mampu memaksimalkan hasil penjualan mitra. Dalam pelatihan kedua 
mitra diajarkan menggunakan sosial media facebook dan istagram seperti yang terlihat pada Gambar 9. berikut ini.

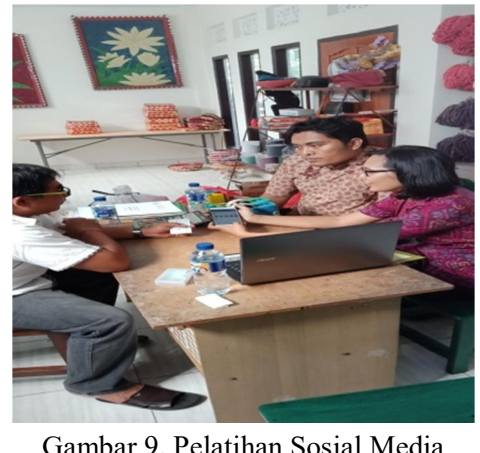

\subsection{Evaluasi Kegiatan}

Tahap terakhir dari kegiatan ini adalah evaluasi kegiatan. Evaluasi kegiatan dilakukan untuk mengukur dan melihat apakah kegiatan yang telah dilakukan telah sesuai dengan perencanaan dan target luaran. Dari hasil evaluasi dapat disimpulkan bahwa, pelaksanaan kegiatan pengabdian kerajinan kerang di Kabupaten Badung telah terlaksana sesuai dengan perencanaan serta sosialisasi sebelumnya. Para peserta pelatihan yaitu kedua UKM sangat antusias dalam kegiatan ini, hal ini dapat terlihat dari keseriusan dan komitmen kedua mitra sangat tinggi. Berdasarkan hasil evaluasi kami memperoleh masukan bahwa kegiatan pelatihan pengenalan pemasaran online dapat dilakukan berkesinambungan karena pelatihan ini dapat memberikan pengetahuan dan ketrampilan kepada mitra yang akan melakukan pemasaran secara online.

\section{PENUTUP}

Dari hasil pelaksanaan program pengabdian ini dapat disimpulkan :

1. Pelaksanaan kegiatan pengabdian kerajinan kerang di Kabupaten Tabanan telah terlaksana sesuai dengan perencanaan serta sosialisasi sebelumnya.
2. Para peserta pelatihan yaitu kedua UKM sangat antusias dalam kegiatan ini, hal ini dapat terlihat dari keseriusan dan komitmen kedua mitra sangat tinggi.

3. Pelatihan pengenalan pemasaran online dapat dilakukan berkesinambungan karena pelatihan ini dapat memberikan pengetahuan dan ketrampilan kepada mitra yang akan melakukan pemasaran secara online.

\section{DAFTAR RUJUKAN}

Anoraga,Panji.2002.Koperasi,Kewirausaha an, dan Usaha Kecil.Rineka Cipta.Jakarta.

Bali Island Map. 2013. Map Pulau Bali. Bali Citra Satelit. www.googlemap.com Diakses tanggal 25 Mei 2016.

Ellworth,jill $\mathrm{H}$ and Methew V.EllsWorth.2012.Pemasaran Internet. Terjemahan Yulianto.Grasindo.Jakarta.

Lovelock Christopher, Wirtz Jochen, Mussry Jacky. 2012. Pemasaran Jasa: Manusia, Teknologi, Strategi. Erlangga. Jakarta.

Ristono, Agus.2009.Manajemen Persediaan.Graha Ilmu.Yogyakarta.

Sutabri,T.2005.Sistem Informasi Manajemen.Andi Offset.Yogyakarta.

Suyanto.M.2003.Strategi Periklanan Pada E-Commerce Perusahaan Top Dunia. Andi Offset.Yogyakarta. 
